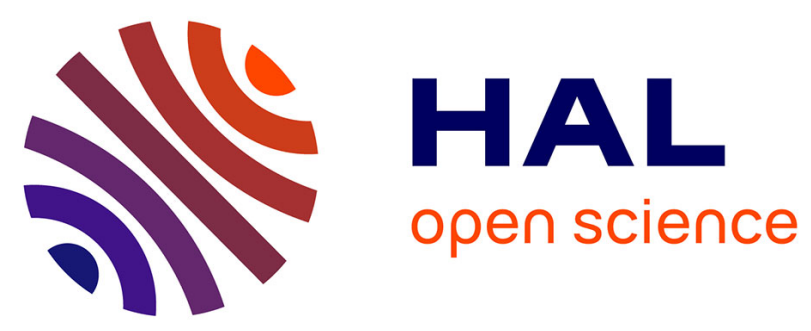

\title{
Study of the Aggregation of Metal Complexes with Asphaltenes Using Gel Permeation Chromatography Inductively Coupled Plasma High-Resolution Mass Spectrometry
}

\author{
Sara Gutierrez Sama, Alain Desprez, Gabriel Krier, Charles-Philippe \\ Lienemann, Jérémie Barbier, Ryszard Lobinski, Caroline Barrère-Mangote, \\ Pierre Giusti, Brice Bouyssière
}

\section{- To cite this version:}

Sara Gutierrez Sama, Alain Desprez, Gabriel Krier, Charles-Philippe Lienemann, Jérémie Barbier, et al.. Study of the Aggregation of Metal Complexes with Asphaltenes Using Gel Permeation Chromatography Inductively Coupled Plasma High-Resolution Mass Spectrometry. Sustainable Energy \& Fuels, 2016, 30 (9), pp.6907 - 6912. 10.1021/acs.energyfuels.6b00559 . hal-03133559

\author{
HAL Id: hal-03133559 \\ https://hal.science/hal-03133559
}

Submitted on 7 Apr 2021

HAL is a multi-disciplinary open access archive for the deposit and dissemination of scientific research documents, whether they are published or not. The documents may come from teaching and research institutions in France or abroad, or from public or private research centers.
L'archive ouverte pluridisciplinaire HAL, est destinée au dépôt et à la diffusion de documents scientifiques de niveau recherche, publiés ou non, émanant des établissements d'enseignement et de recherche français ou étrangers, des laboratoires publics ou privés. 


\section{Study of the aggregation of metal-complexes with}

\section{asphaltenes using Gel Permeation Chromatography}

\section{Inductively Coupled Plasma High Resolution Mass}

\section{Spectrometry}

Sara GUTIERREZ SAMA ${ }^{+s^{*}}$, Alain DESPREZ ${ }^{\dagger+}$, Gabriel KRIER ${ }^{\ddagger}$, Charles-Philippe

LIENEMANN , Jérémie BARBIER , Ryszard LOBINSKI ${ }^{\dagger *}$, Caroline BARRERE-MANGOTE ${ }^{\S^{*}}$,

Pierre GIUSTI ${ }^{s^{*}}$, Brice BOUYSSIERE ${ }^{\dagger *}$

${ }^{\dagger}$ CNRS/UPPA, UMR 5254, LCABIE, Hélioparc, 2 Av. Pr. Angot, 64053 Pau, France

UL, LCP-A2MC, 1 Bd. Arago, Technopôle Metz 2000, 57070 Metz, France

${ }^{\S}$ TOTAL Refining \& Chemicals, Total Research \& Technology, Gonfreville, BP 27, F-76700

Harfleur, France

IFPEn, Rond Point de l'échangeur, 69360 Solaize, France

*Joint Laboratory C2MC: Complex Matrices Molecular Characterization, Total Research \&

Technology, Gonfreville, BP 27, F-76700 Harfleur, France 


\section{ABSTRACT}

Gel Permeation Chromatography Inductively Coupled Plasma High Resolution Mass

Spectrometry (GPC ICP HR MS) was used for the understanding of the evolution of two crude oil cut samples after their dilution. We firstly studied different method parameters in order to compare two GPC procedures already published (flow rate, column set, presence or not of the THF stabilizer). Thus, the principal parameters affecting the molecular size distribution and its evolution were demonstrated. The column set and flow rate can affect drastically the molecular size distribution of the sample. Moreover an evolution of the size distribution of the complexes of vanadium, nickel and sulfur into higher molecular weight compounds was observed over time. The study led to the recommendation of the sample preparation to the same day of the analysis in order to obtain reproducible data.

\section{INTRODUCTION}

Crude oil is a complex hydrocarbon mixture that can be separated by distillation, according to the boiling point, in different fractions. Heavy (high boiling point) fractions such as Atmospheric Residues (AR) or Vacuum Residues (VR), with boiling points over 390 and $550^{\circ} \mathrm{C}$ respectively, have impurities such as heteroatoms like sulfur, in concentrations going up to several percent, and heavy metals. Among these metals the most undesirable and abundant ones are vanadium and nickel, present in concentrations going up to several hundreds of parts per million (ppm) ${ }^{1,2}$, depending on their geological origin ${ }^{3-5}$.

Heavy fractions and heavy oils are more and more used in petrochemical industry because they became one of the most abundant hydrocarbon sources. However, they have to be previously transformed by catalytic cracking processes ${ }^{1,5,6}$. Vanadium, nickel and sulfur present poison the 
catalysts used during oil refining processes, leading to corrosion of the equipment, environmental pollution and the contamination of petroleum-related products ${ }^{5}$. Therefore, these elements must be removed from the heavy fractions by hydrodemetallation and hydrodesulfurization.

Information on the size and chemical form (speciation) of vanadium, nickel and sulfur complexes is of great interest to choose the porosity of refining catalysts ${ }^{3,7,8}$.

The main approaches for metal and sulfur speciation in petroleum samples are based on the combination of chromatographic separation and element specific detection. Gel Permeation Chromatography (GPC), a type of Size Exclusion Chromatography (SEC), is widely used to obtain information on the molecular weight (more concretely on the hydrodynamic volume) of the molecules of high boiling temperature products $[3,8-12]$. The most used detection techniques for the analysis of oil are Atomic Absorption Spectrometry (AAS), X-Ray Fluorescence (XRF) or Inductively Coupled Plasma (ICP) Atomic Emission Spectrometry (AES) ${ }^{2,3,7}$. More recently, detection has been improved using ICP Mass Spectrometry (MS) ${ }^{2,7,13-15}$, which offers lower detection limits and multielement measurements, High-Resolution (HR) instruments allowing the resolution of the isobaric interferences ${ }^{11,12}$.

This study discusses size distribution of vanadium, nickel and sulfur-containing compounds of an AR and a VR using the GPC ICP HR MS. The goal of this work was the optimization and the understanding of the most important parameters of this technique (flow rate, column set), developed in previous works ${ }^{8,14,16}$. Thus, evolution over 254 days of the aggregates size profiles is also here discussed.

\section{MATERIALS AND METHODS}


Solvents, samples and solutions. THF, HPLC grade, without stabilizer (Scharlau) and THF Multisolvent ${ }^{\circledR}$ GPC grade ACS stabilized with 250 ppm of BHT (Scharlau) were used as solvents for the sample preparation and as mobile phases. BHT is used as a stabilizer for the THF in order to avoid any peroxidation.

Samples analyzed, an AR from South America and a VR from Middle East, are described in Table S1 (in supporting information file). The samples were analyzed with dilution factors of 100 for the AR and 160 for the VR. Dilutions were made by weight, using a precision scales. These samples were chosen as they are both used as standard samples by IFP EN and TOTAL.

Methodology. The study of the evolution overtime was done with solutions prepared the first day of the study and solutions prepared more than 4 months in advance of the study (stored in amber glass vials at room temperature without any regular shaking). These solutions were injected at different times during the same week to achieve a 254-day kinetics.

Instrumentation. A double focusing sector field inductively coupled plasma mass spectrometer (Element XR, Thermo Fisher Scientific, Germany) was used to access the spectrally interfered isotopes of ${ }^{32} \mathrm{~S},{ }^{51} \mathrm{~V}$, and ${ }^{58} \mathrm{Ni}$ under the working conditions given in Table Table S2 (in supporting information file). These were optimized daily using a $1.0 \mathrm{ng} / \mathrm{g}$ multielement tuning solution of $\mathrm{Ag}, \mathrm{Al}, \mathrm{B}, \mathrm{Ba}, \mathrm{Ca}, \mathrm{Cd}, \mathrm{Co}, \mathrm{Cr}, \mathrm{Cu}, \mathrm{Fe}, \mathrm{In}, \mathrm{K}, \mathrm{Li}, \mathrm{Mg}, \mathrm{Mn}, \mathrm{Mo}$, $\mathrm{Na}, \mathrm{Ni}, \mathrm{P}, \mathrm{Pb}, \mathrm{Sc}, \mathrm{Si}, \mathrm{Sn}, \mathrm{Ti}, \mathrm{V}, \mathrm{Zn}$, and $\mathrm{Y}$ in THF. The instrument was equipped with a quartz injector (inner diameter $1.0 \mathrm{~mm}$ ) and Pt sampler (orifice diameter $1.1 \mathrm{~mm}$ ) and skimmer (orifice diameter $0.8 \mathrm{~mm}$ ) cones. An $\mathrm{O}_{2}$ gas flow was added to avoid carbon deposition. Mass offset was applied to the data acquisition method to compensate the mass drift coming from the magnet sector. 
The mass spectrometer was fitted with a modified DS-5 microflow total consumption nebulizer (CETAC, Omaha, NE) mounted with a laboratory-made single pass jacketed glass

spray chamber ${ }^{17,18}$. It was thermostatted at $60^{\circ} \mathrm{C}$ by a water/glycol mixture using a temperaturecontrolled bath circulator (Neslab RTE-111, Thermo Fisher Scientific, Waltham, MA).

The carrier solution and the mobile phase were delivered by a Dionex High-Performance Liquid Chromatography (HPLC) system with an UltiMate 3000 microflow pump, an UltiMate 3000 autosampler and a low port-to-port dead-volume microinjection valve.

Chromatographic separation was performed by two different sets of three GPC columns connected in series, described in Table 1. A Styragel guard column (4.6 mm inner diameter, 30 mm length, 10000Da exclusion limit) was used before the column set Col W.

$20 \mu \mathrm{L}$ of the samples were injected and eluted isocratically at two different flow rates $(0.7$ and $1 \mathrm{~mL} / \mathrm{min}$ ) of the solvent for $120 \mathrm{~min}$. A post-column splitter was used in order to introduce only $40 \mu \mathrm{L} / \mathrm{min}$ in the ICP MS, sending the rest to the waste.

Excel was used for the integration of the chromatograms obtained. On all the presented chromatograms, the intensity was normalized with respect to the total area obtained for the represented isotope.

\section{RESULTS AND DISCUSSION}

Repeatability of the method. Figure 1 shows an example of the chromatograms obtained for vanadium, nickel and sulfur-containing compounds. It can be observed that vanadium-containing compounds follow a trimodal distribution, indicating the presence of three different types of compounds or aggregates of different molecular weight. In order to compare our chromatograms, four integration intervals or fractions were defined according to the trimodal profile obtained for 
vanadium-containing compounds: fraction $1(\mathrm{~F} 1)$, fraction $2(\mathrm{~F} 2)$ and fraction $3(\mathrm{~F} 3)$, corresponding to High Molecular Weight (HMW), Medium Molecular Weight (MMW) and Low Molecular Weight (LMW) compounds respectively, and the tailing fraction (F4). The integration boundaries were defined at $15-22-27-30-54 \mathrm{~mL}$ according to the chromatogram obtained for vanadium-containing compounds at $0.7 \mathrm{~mL} / \mathrm{min}$.

HMW compounds are composed of large aggregates of molecules, MMW compounds are composed of medium size aggregates and LMW compounds are composed of free molecules and also small aggregates, while the reinjection of the tailing fraction in GPC ICP HR MS shows that it contains HMW, MMW and LMW aggregates, presenting a size distribution comparable to the original chromatogram of the sample ${ }^{14}$. As can be seen in Figure 1, nickel and sulfur-containing compounds also follow a multimodal distribution.

The repeatability of the method was studied by analyzing fresh solutions of the two samples (injected one hour after their preparation) once a day during 6 consecutive days under the same conditions, which made possible the calculation of the Relative Standard Deviation (RSD) with respect to the area of the chromatograms (Table 2). Figure S1 represents the overlap of vanadium, nickel and sulfur chromatograms obtained for the analysis of both samples injected freshly during 6 consecutive days. It can be seen on these chromatograms and in the Table 2 that the results obtained were identical. The good RSD obtained on 6 replicates for the integrated areas was of less than $5 \%$ (except for the HMW fraction, which represents the lowest area, with a RSD around $10 \%$ ) and is linked to the stability of the system, the sample preparation and the integration. This allows the use of the integration of the different fractions to compare the results obtained between different parameters and samples, taking into account the error calculated from 
several fresh solutions of the two samples for each of the different experiments under different conditions.

Effect of the mobile phase flow rate. The influence of the flow rate on the size of the aggregates was studied. Two GPC ICP HR MS experiments were carried out at different flow rates $(0.7$ and $1 \mathrm{~mL} / \mathrm{min})$, according the internal method used in IFP $\mathrm{EN}^{14}$ and TOTAL ${ }^{16}$ laboratories, for the two samples, using stabilized THF as solvent and as mobile phase and the column set $\mathrm{Col} \mathrm{A}$. The chromatograms obtained for vanadium-containing compounds are given in Figure 2.

The chromatogram obtained for vanadium aggregates at $0.7 \mathrm{~mL} / \mathrm{min}$ (blue line) presented in Figure 2 is shifted towards lower elution volumes in comparison with the chromatogram obtained at $1 \mathrm{~mL} / \mathrm{min}$ (red line). This result could be explained by the flow-induced degradation in SEC columns when increasing the mobile-phase velocity ${ }^{19,20}$.

However, in order to process our data taking this shift into account, we changed the integration boundaries to $13-16-19-22-39 \mathrm{~mL}$ for $1 \mathrm{~mL} / \mathrm{min}$. Figure 3 shows the size distributions of the four fractions as a percentage of the total area of the chromatogram obtained for vanadium aggregates and the increase of HMW and MMW compounds when increasing the mobile-phase flow rate can be observed. Meanwhile, the tailing fraction decreases at higher flow rate, which could be explained as the decrease in the interaction between the metals on the surface of the aggregates and the stationary phase with the mobile-phase velocity, because it has less time to interact.

The same behavior is observed for nickel and sulfur-containing compounds. Their corresponding size profiles are given as supplementary material. The rest of the chromatograms obtained for nickel and sulfur-containing compounds are not presented in this paper as the same 
behavior of the aggregates of the three elements analyzed is observed in all cases and can be illustrated with the results obtained only for vanadium-containing compounds.

Influence of the presence of stabilizer (BHT) in the THF. The influence of the presence of the stabilizer in the THF on the chromatogram of aggregates of both samples was studied. Two GPC ICP HR MS experiments were carried out using THF and stabilized THF for the sample preparation and as mobile phases. The chromatograms obtained for vanadium-containing compounds are given in Figure 4. These chromatograms were similar but showed some differences for HMW aggregates and the tailing part. Similar distribution of vanadium in THF and stabilized THF of the two samples analyzed is observed (also see Figure S2 in supporting information file). The percentage of the total area of the chromatogram for the four fractions was obtained by measuring the area of the different fractions from the GPC ICP HR MS chromatograms. The increase of HMW aggregates in THF compared to stabilized THF is compensated by the decrease of the fraction 4 (tailing). These results seem to indicate that the effect of the stabilizer has not an important impact on size distribution. Moreover, the fact that the chromatograms obtained for the two samples analyzed after 8 months of preparation using (as both solvents and mobile phases) stabilized THF (blue line) and THF (red line) are also very similar could prove that the stabilizer has no influence on size distribution overtime (Figure 5).

Comparison between the use of different columns. The influence of the chromatographic stationary phase on the size distribution of the aggregates was studied. The results obtained with two different sets of columns at a flow rate of $1 \mathrm{~mL} / \mathrm{min}$ are compared in Figure 6. This figure shows a higher proportion of HMW compounds using the column set Col W (blue line) in stabilized THF, while the chromatograms present higher proportion of LMW compounds with the column set Col A (red line) in THF. This result could mean, as we compare aggregation 
states, the existence of different interaction with the stationary phase depending on the column set and higher shear degradation using the column set Col A compared to Col W. The breakdown of the high-molar-mass molecules or aggregates because of the shear forces ${ }^{20,21}$ results in a degradation phenomenon converting HMW aggregates into compounds of lower molecular weight and thus decreasing the amount and size of HMW aggregate to the benefit of LMW compounds.

The effect of the stabilizer was disregarded, according to the results obtained in the previous section.

Study of the evolution of the samples in time. The evolution of the molecular size of the aggregates was studied for sample solutions of $0,3,7,26$ (only for the VR sample), 95 and 254 days old. To compare the results obtained, the parameters of solvent flow rate and column set were fixed. GPC ICP HR MS experiments were carried out at $0.7 \mathrm{~mL} / \mathrm{min}$, using the column set Col A. As THF is potentially dangerous because of its tendency to form highly explosive peroxides when stored in air, exposed to UV light or heat, and after observing that the presence of stabilizer does not seem to influence size distribution, stabilized THF was used for the preparation of the samples and as mobile phase in this part of the work. The chromatograms obtained for vanadium-containing compounds of AR and VR solutions under these conditions are given in Figure 7. The increase in the peak height corresponding to HMW compounds containing vanadium and the decrease of MMW and LMW compounds was observed. Such phenomena are also observed for $\mathrm{Ni}$ compounds in the AR and VR. This could mean that the aggregation of lower molecular weight compounds took place to form HMW ones. This observation is supported by the calculations presented in Table 3 where it can be seen the correspondence between the increase of the proportion of HMW aggregates and the decrease of 
the rest of the fractions between the first and the last days of the experiment. It can be observed that $\mathrm{Ni}$ is the more reactive element with an increase between 10 to $20 \%$ of the HMW overtime. During the same time, a decrease of the MMW fractions for all the elements observed, but also a decrease of the tailing and the LMW fractions for Ni and V in both petroleum products and $\mathrm{S}$ in the VR.

The evolution trend of the size distribution of vanadium aggregates can be clearly seen in Figure S3 (in supporting information file). The evolution showed a fast kinetics of the process. Then it slows down.

\section{CONCLUSION}

This study shows that different types of aggregates of different size that can have interaction with the GPC phase were observed: multimodal profiles were obtained for vanadium, nickel and sulfur-containing compounds.

Significant differences were found depending on the solvent flow rate and the columns used, which seem to have an influence on the size distribution of vanadium, nickel and sulfur aggregates, whereas the presence of the stabilizer BHT in the solvent does not seem to have an important role. Working under the conditions giving the lowest shear rate possible could allow the study of the native aggregation state of the compounds in the sample. The aggregation overtime of vanadium, nickel and sulfur compounds was observed, mainly during the first month, therefore samples must be prepared freshly every day to compare the results. 


\section{FIGURES}

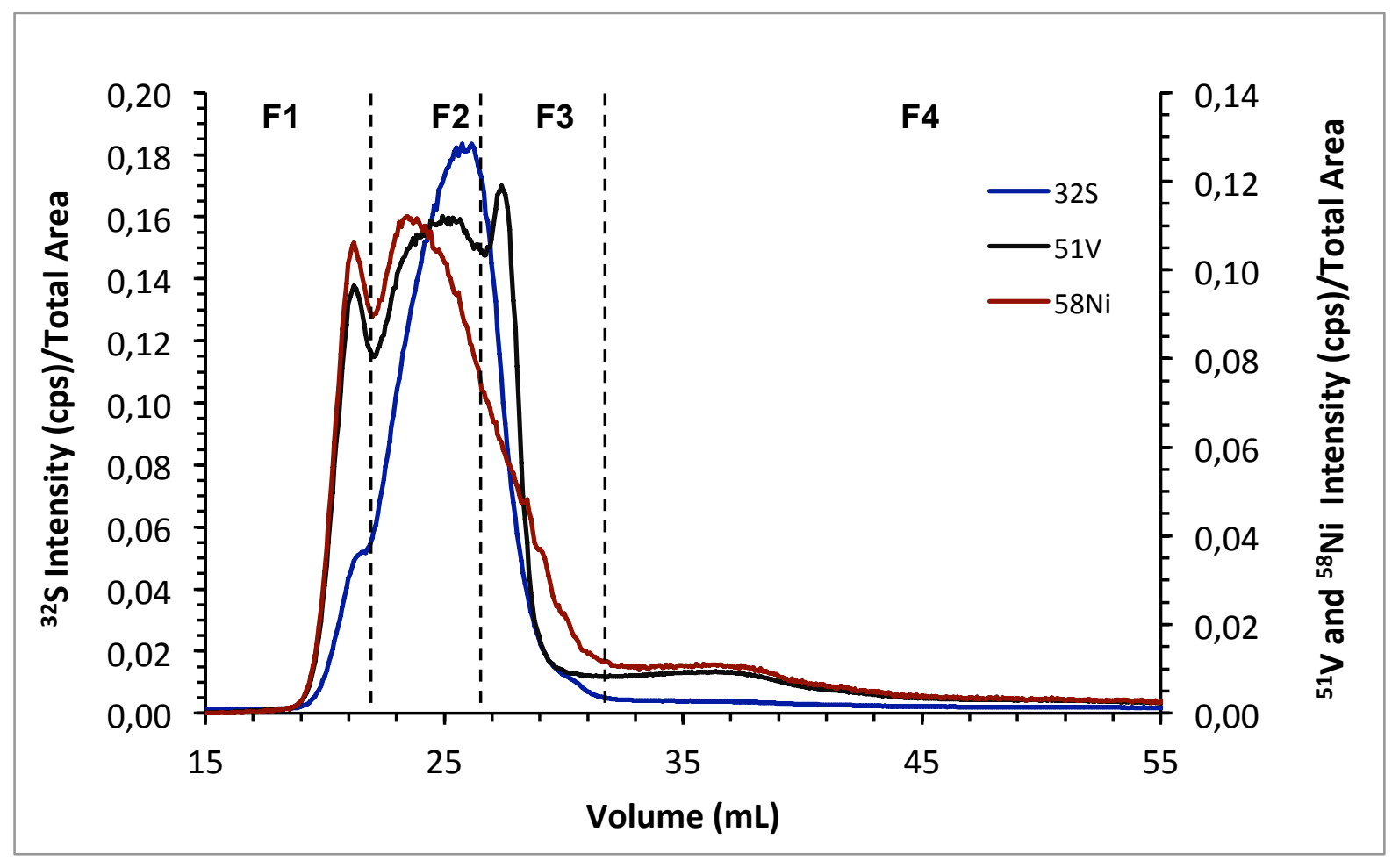

Figure 1. Integration limits for GPC ICP HR MS chromatograms normalized with respect to their total area of the vanadium, nickel and sulfur-containing compounds in the AR sample, obtained in stabilized THF at $0.7 \mathrm{~mL} / \mathrm{min}$, using the column set Col A. 


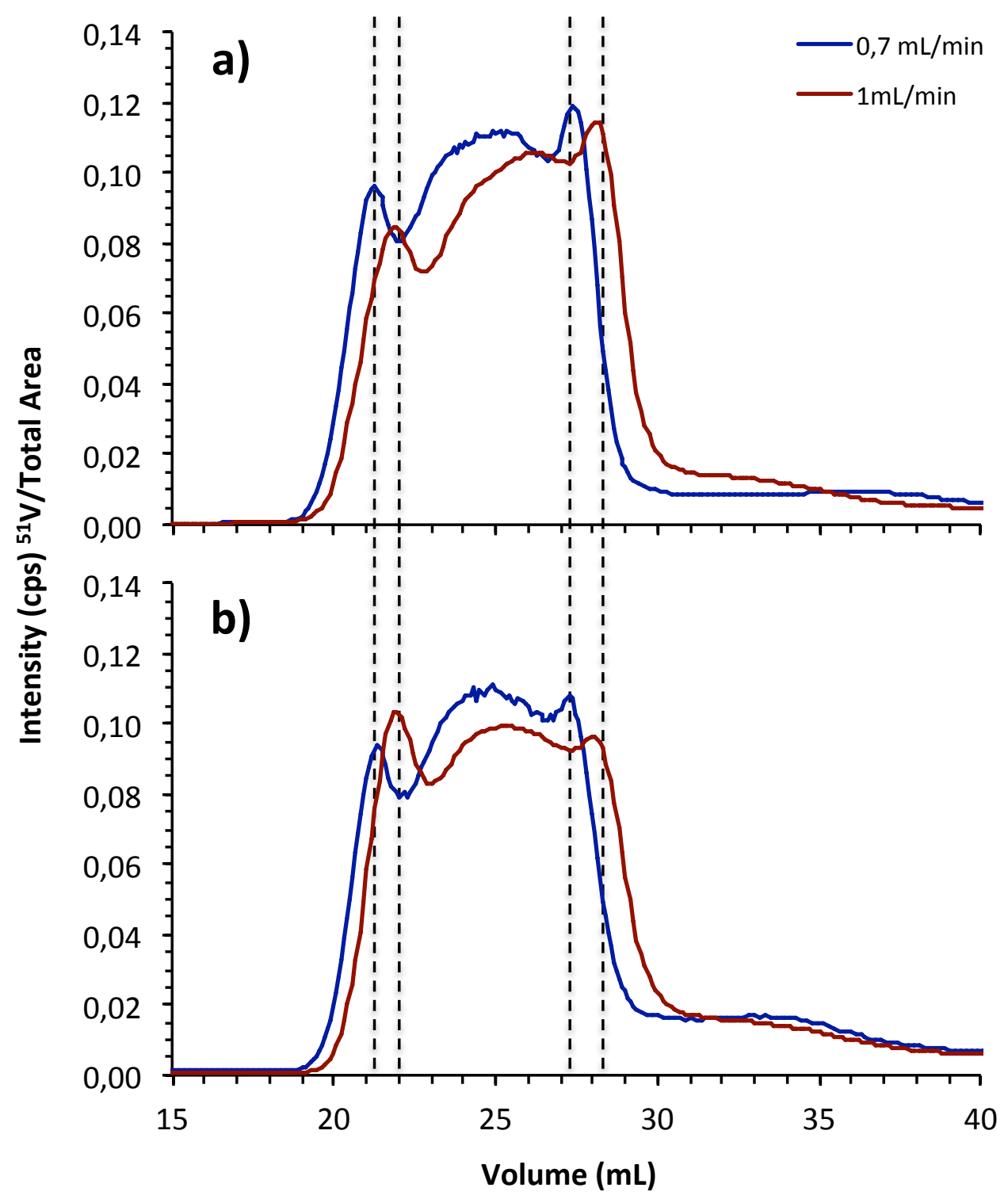

Figure 2. Comparison of the normalized chromatograms with respect to their total area obtained for vanadium aggregates of fresh solutions using different solvent flow rates for stabilized THF and the column set Col A, for both (a) AR and (b) VR samples. 


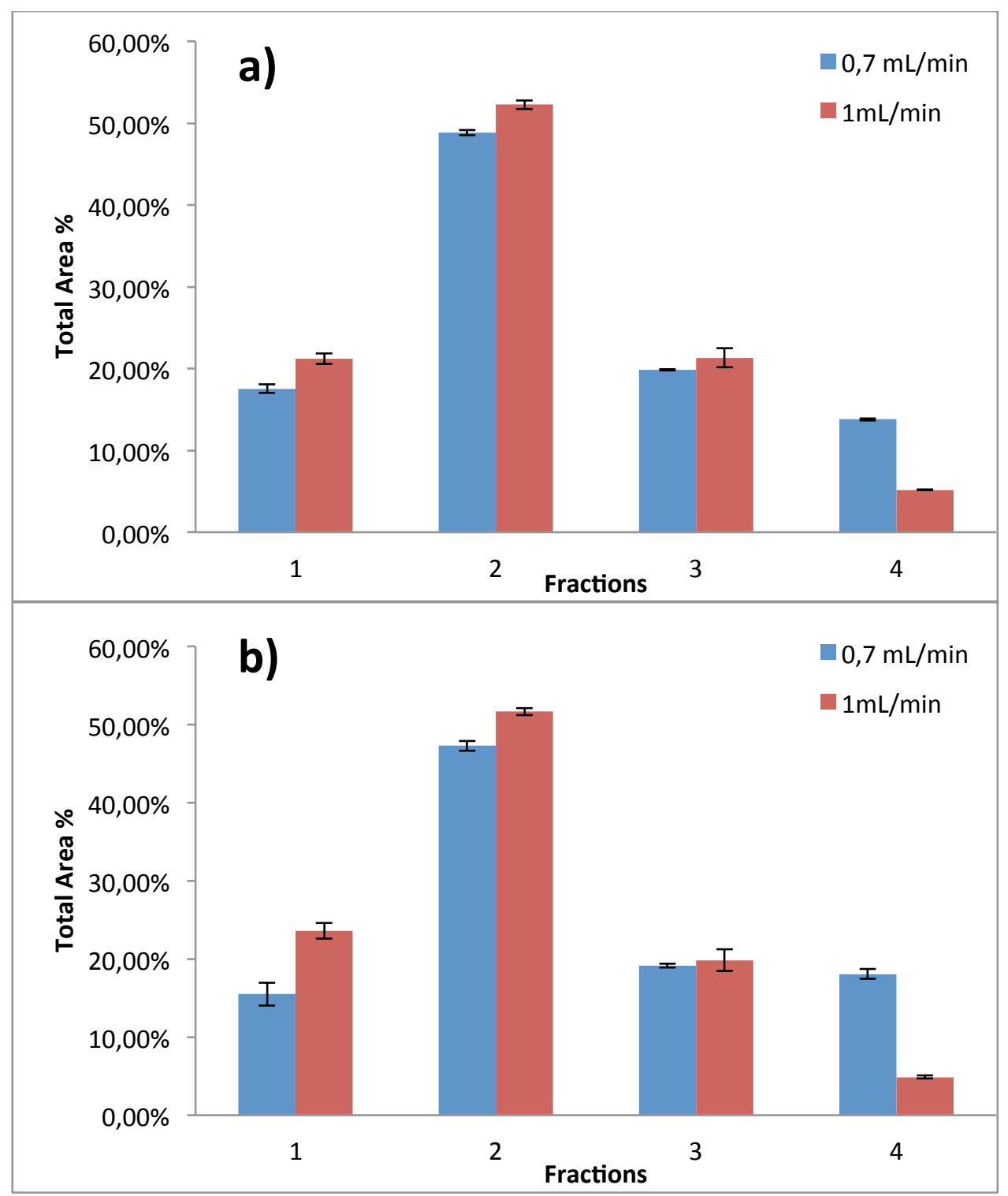

Figure 3. Comparison of the size distributions of the four fractions as a percentage of the total area of the chromatogram obtained for vanadium aggregates of fresh solutions using different solvent flow rates for stabilized THF and the column set Col A for both (a) AR and (b) VR samples. 


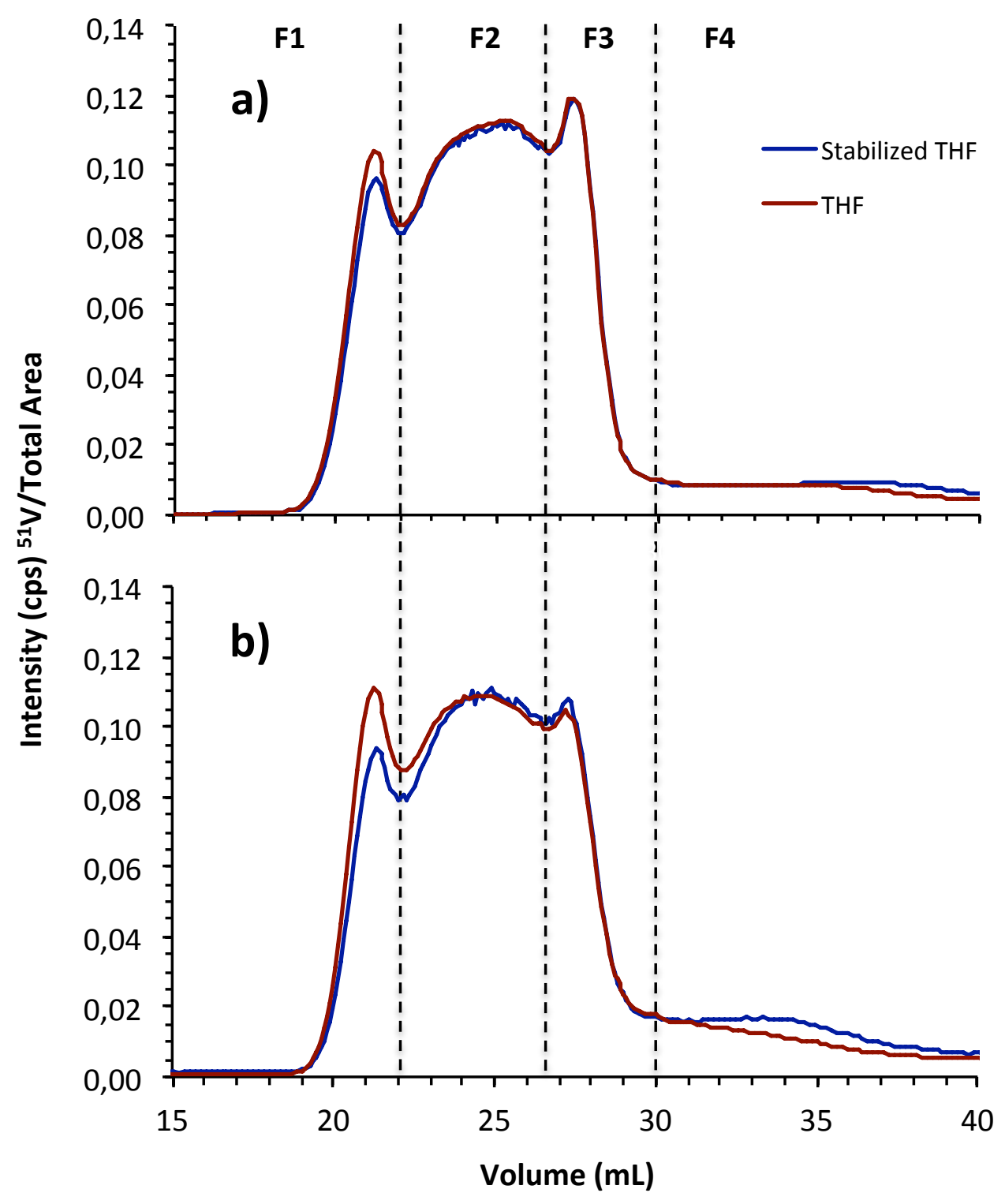

Figure 4. Comparison of the normalized chromatograms with respect to their total area obtained for vanadium aggregates of fresh solutions using THF stabilized or not for the sample preparation and as mobile phase, at $0.7 \mathrm{~mL} / \mathrm{min}$ and using the column set Col A for both (a) AR and (b) VR samples. 


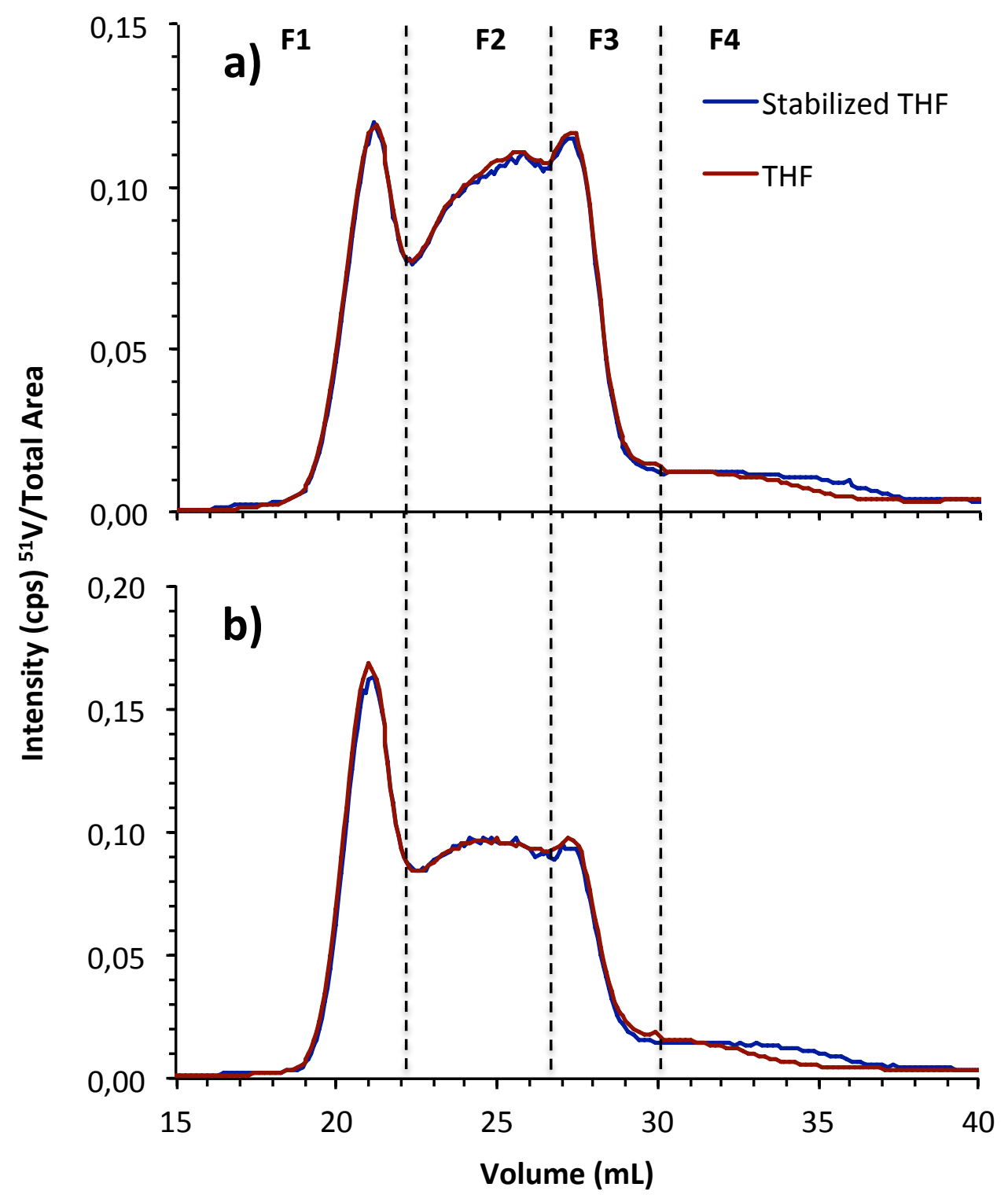

Figure 5. Comparison of the normalized chromatograms with respect to their total area obtained for vanadium aggregates of fresh solutions using THF stabilized or not for the sample preparation and as mobile phase at $0.7 \mathrm{~mL} / \mathrm{min}$ and using the column set Col A for both (a) AR and (b) VR samples of 254 days old for stabilized THF and of 240 days old for THF. 


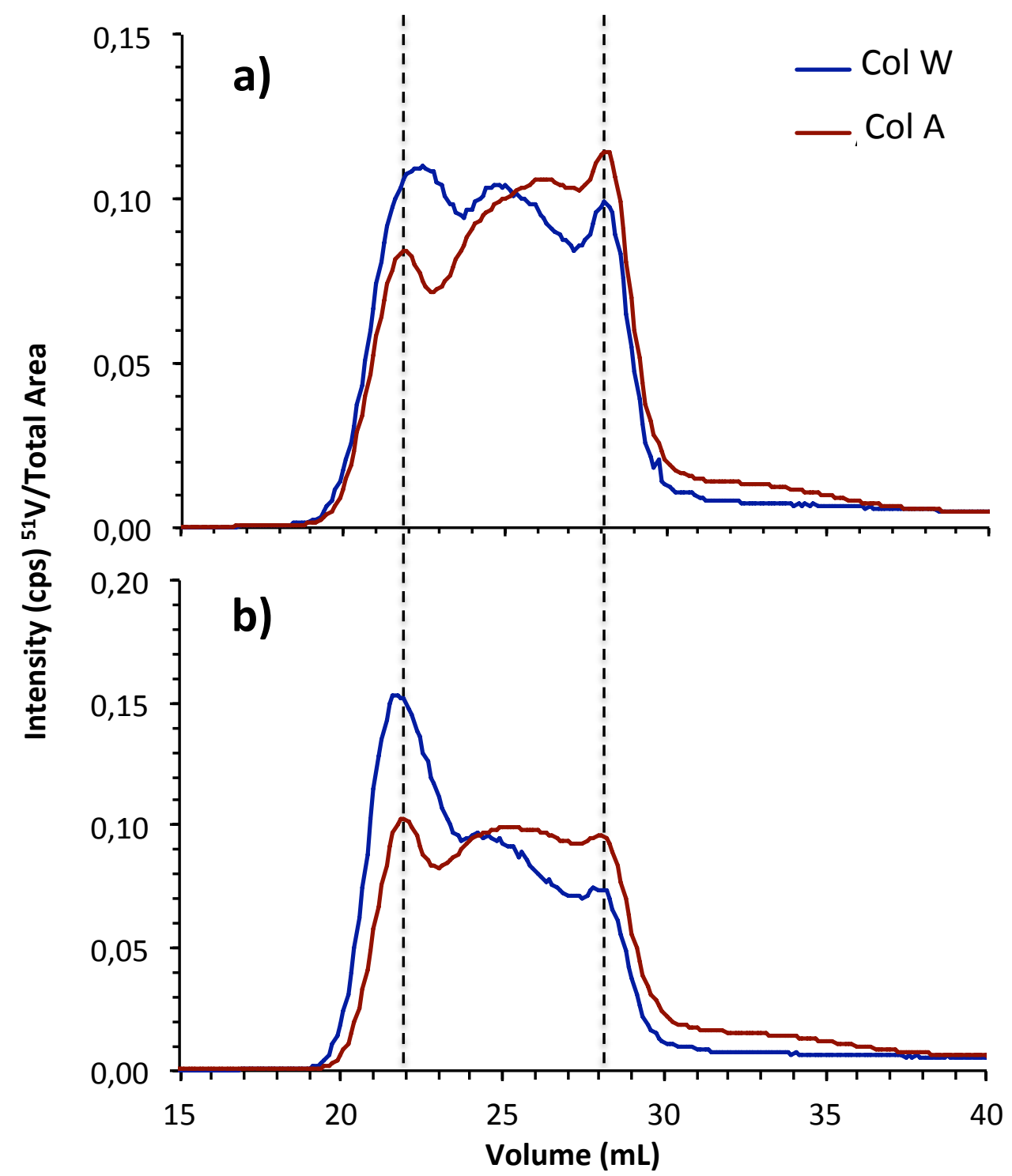

Figure 6. Comparison of the normalized chromatograms with respect to their total area obtained for vanadium aggregates of fresh solutions using different column sets (Col W in THF and Col A in stabilized THF) at $1 \mathrm{~mL} / \mathrm{min}$, for both (a) AR and (b) VR samples. 


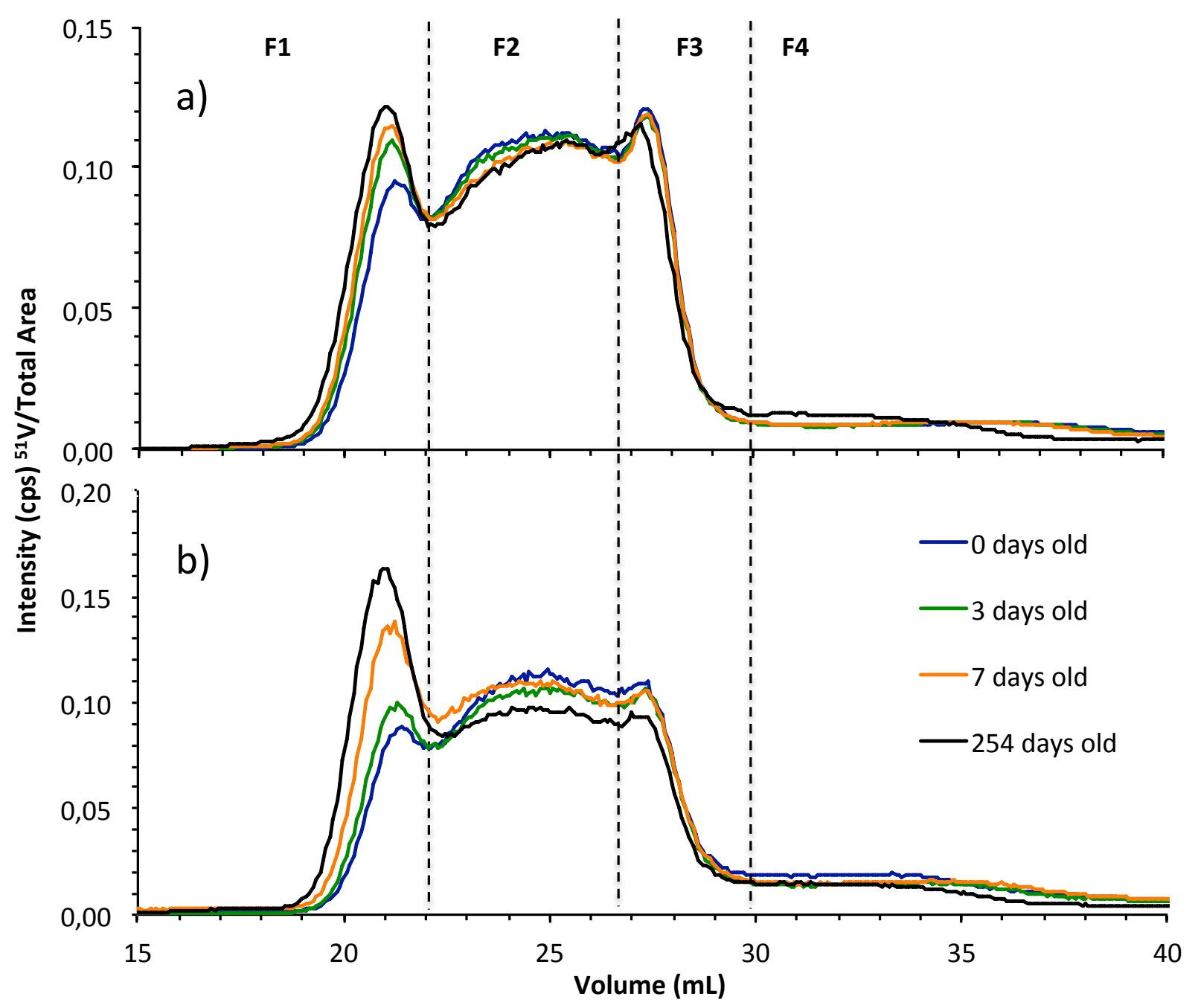

Figure 7. Evolution overtime of the normalized graphs with respect to their total area obtained for vanadium aggregates of the AR a) and VR b) solutions in stabilized THF, at $0.7 \mathrm{~mL} / \mathrm{min}$, using the column set $\mathrm{Col} \mathrm{A}$. 
TABLES

Table 1. Characteristics of the two GPC column sets used.

\begin{tabular}{lll}
\hline Column set & \multicolumn{1}{c}{ Col A } & \multicolumn{1}{c}{ Col W } \\
\hline GPC columns & Agilent PLgel MIXED-D & Waters Styragel \\
ID (mm) & 7.5 & 7.8 \\
Length $(\mathbf{m m})$ & 300 & 300 \\
Stationary phase & Polystyrene-divinylbenzene & Styrene-divinylbenzene \\
Exclusion limit (Da) & $200-400000$ & $1000-600000$ \\
Columns used & $100,10^{3}$ and $10^{5} \AA$ & HR4, HR2 and HR0.5 \\
Particle size ( $\mathbf{\mu m})$ & 5 & 5 \\
\hline
\end{tabular}


Table 2. Repeatability (6 analysis on 6 consecutive days) of the percentage of the four fractions obtained for both AR and VR samples.

\begin{tabular}{|c|c|c|c|c|c|c|c|c|c|c|}
\hline \multirow[t]{2}{*}{ Sample } & \multirow[t]{2}{*}{ Fraction } & \multicolumn{3}{|c|}{${ }^{32} \mathrm{~S}$} & \multicolumn{3}{|c|}{${ }^{51} \mathbf{V}$} & \multicolumn{3}{|c|}{${ }^{58} \mathbf{N i}$} \\
\hline & & $\%$ & $+/-$ & $\begin{array}{r}\text { RSD } \\
(\%)\end{array}$ & $\%$ & $+/-$ & $\begin{array}{r}\text { RSD } \\
(\%)\end{array}$ & $\%$ & $+/-$ & $\begin{array}{r}\text { RSD } \\
(\%)\end{array}$ \\
\hline \multirow{5}{*}{$\mathbf{A R}$} & F1 (HMW) & 4.1 & 0.3 & 7.3 & 11.0 & 0.7 & 6.4 & 12.6 & 0.8 & 6.3 \\
\hline & F2 (MMW) & 50.9 & 1.2 & 2.4 & 46.8 & 0.4 & 0.9 & 47.7 & 0.2 & 0.4 \\
\hline & F3 (LMW) & 29.6 & 0.9 & 3.0 & 25.5 & 0.8 & 3.1 & 17.9 & 0.5 & 2.8 \\
\hline & F4 (Tailing) & 15.4 & 0.6 & 3.9 & 16.7 & 0.3 & 1.8 & 21.8 & 0.5 & 2.3 \\
\hline & Total & 100 & & & 100 & & & 100 & & \\
\hline \multirow{5}{*}{ VR } & F1 (HMW) & 4.1 & 0.5 & 12.2 & 10.9 & 1.1 & 10.1 & 11.5 & 1.1 & 9.6 \\
\hline & F2 (MMW) & 61.1 & 1.7 & 2.7 & 48.1 & 0.2 & 0.4 & 47.0 & 0.3 & 0.6 \\
\hline & F3 (LMW) & 26.2 & 1.7 & 6.5 & 22.6 & 0.9 & 4.0 & 17.0 & 0.4 & 2.4 \\
\hline & F4 (Tailing) & 8.6 & 0.4 & 4.7 & 18.4 & 0.2 & 1.1 & 24.6 & 0.5 & 2.0 \\
\hline & Total & 100 & & & 100 & & & 100 & & \\
\hline
\end{tabular}


Table 3. Difference of the percentage of the four fractions obtained for the three elements analyzed at $0.7 \mathrm{~mL} / \mathrm{min}$, using the column set $\mathrm{Col} \mathrm{A}$, between the 254-day-old AR and VR samples and the fresh samples.

\begin{tabular}{llccc}
\hline \% Total Area & ${ }^{32} \mathbf{S}$ & ${ }^{\mathbf{5 1}} \mathbf{V}$ & ${ }^{\mathbf{5 8}} \mathbf{N i}$ \\
\hline \multirow{4}{*}{ AR } & HMW & 1.0 & 7.1 & 11.1 \\
& LMW & -11.4 & -2.9 & -4.8 \\
& Tailing & 4.1 & -1.7 & -2.9 \\
& Total & 6.3 & -2.5 & -3.4 \\
& HMW & 0.0 & 0.0 & 0.0 \\
\hline \multirow{3}{*}{ VR } & MMW & 5.7 & 15.9 & 18.1 \\
& LMW & -3.8 & -5.7 & -6.2 \\
& Tailing & -0.6 & -3.1 & -3.7 \\
& Total & -1.3 & -7.1 & -8.5 \\
\hline
\end{tabular}




\section{AUTHOR INFORMATION}

\section{Corresponding Author}

* Telephone: +33 559407 752. Fax: +33 559407 674. E-mail: brice.bouyssiere@univ-pau.fr.

\section{Notes}

The authors declare no competing financial interest.

\section{ASSOCIATED CONTENT}

\section{Supporting Information}

In Tables S1 and S2, samples AR and VR and the ICP HR MS experimental conditions are described respectively. Figure S1 with the chromatograms obtained for the repeatability study is presented supporting Table 2. The similar distribution of vanadium in THF and stabilized THF of the two samples analyzed observed in Figure 4 can also be seen in Figure S2 as histograms and Figure S3 shows the evolution observed over time as a diagram with curves. Chromatograms obtained for nickel and sulfur-containing compounds using different solvent flow rates are presented in Figures S4 and S5. This material is available free of charge via the Internet at http://pubs.acs.org.

\section{ACKNOWLEDGEMENTS}

The financial support of the Conseil Régional d'Aquitaine (20071303002PFM) and FEDER (31486/08011464) is acknowledged.

\section{REFERENCES}

(1) Ali, M. F.; Abbas, S. Fuel Process. Technol. 2006, 87 (7), 573-584. 
(2) Duyck, C.; Miekeley, N.; Porto da Silveira, C. L.; Aucélio, R. Q.; Campos, R. C.; Grinberg, P.; Brandão, G. P. Spectrochim. Acta Part B At. Spectrosc. 2007, 62 (9), 939951.

(3) Caumette, G.; Lienemann, C.-P.; Merdrignac, I.; Bouyssiere, B.; Lobinski, R. J. Anal. At. Spectrom. 2009, 24 (3), 263-276.

(4) Barwise, A. J. G. Energy Fuels 1990, 4 (6), 647-652.

(5) Lopez, L.; Lo Monaco, S.; Richardson, M. Org Geochem 1998, 29 (1-3), 613-629.

(6) Reynolds, J. G. Pet. Sci. Technol. 2001, 19 (7-8), 979-1007.

(7) Hausler, D.; Carlson, R. Spectrochim. Acta Rev 1991, 14, 125-140.

(8) Barbier, J.; Marques, J.; Caumette, G.; Merdrignac, I.; Bouyssiere, B.; Lobinski, R.; Lienemann, C.-P. Fuel Process. Technol. 2014, 119, 185-189.

(9) Biggs, W. R.; Brown, R. J.; Fetzer, J. C. Energy Fuels 1987, 1 (3), 257-262.

(10) Merdrignac, I.; Truchy, C.; Robert, E.; Guibard, I.; Kressmann, S. Pet. Sci. Technol. 2004, 22 (7-8), 1003-1022.

(11) Acevedo, S.; Guzmán, K.; Labrador, H.; Carrier, H.; Bouyssiere, B.; Lobinski, R. Energy Fuels 2012, 26 (8), 4968-4977.

(12) Pohl, P.; Dural, J.; Vorapalawut, N.; Merdrignac, I.; Lienemann, C. P.; Carrier, H.; Grassl, B.; Bouyssiere, B.; Lobinski, R. J. Anal. At. Spectrom. 2010, 25 (12), 1974-1977.

(13) Pohl, P.; Vorapalawut, N.; Bouyssiere, B.; Carrier, H.; Lobinski, R. J. Anal. At. Spectrom. 2010, 25 (5), 704-709.

(14) Caumette, G.; Lienemann, C.-P.; Merdrignac, I.; Bouyssiere, B.; Lobinski, R. J. Anal. At. Spectrom. 2010, 25 (7), 1123-1129.

(15) Duyck, C.; Miekeley, N.; Porto da Silveira, C. L.; Szatmari, P. Spectrochim. Acta Part B At. Spectrosc. 2002, 57 (12), 1979-1990.

(16) Desprez, A.; Bouyssiere, B.; Arnaudguilhem, C.; Krier, G.; Vernex-Loset, L.; Giusti, P. Energy Fuels 2014, 28 (6), 3730-3737.

(17) Caumette, G.; Lienemann, C.-P.; Merdrignac, I.; Paucot, H.; Bouyssiere, B.; Lobinski, R. Talanta 2009, 80 (2), 1039-1043.

(18) Giusti, P.; Nuevo Ordóñez, Y.; Philippe Lienemann, C.; Schaumlöffel, D.; Bouyssiere, B.; Łobiński, R. J Anal Spectrom 2007, 22 (1), 88-92.

(19) Kirkland, J. J. J. Chromatogr. 1976, 125, 231-250.

(20) Striegel, A.M. J. Liq. Chromatogr. Relat. Technol. 2008, 31 (20), 3105-3114.

(21) Slagowski, E. L.; Fetters, L. J.; Macintyre, D. Macromolecules 1974, 7 (3), 394-396. 